\title{
Poly(bromoethyl acrylate): A reactive precursor for the synthesis of functional RAFT materials
}

\author{
Tammie R. Barlow, Johannes C. Brendel ${ }^{\dagger, t}$ and Sébastien Perrier ${ }^{*,+, *}$ \\ ${ }^{\dagger}$ Department of Chemistry, University of Warwick, Gibbet Hill Road, Coventry, CV4 7AL, United \\ Kingdom
}

${ }^{\ddagger}$ Faculty of Pharmacy and Pharmaceutical Sciences, Monash University, 381 Royal Parade, Parkville, Victoria 3052, Australia.

Correspondence to: S.Perrier (E - mail: s.perrier@warwick.ac.uk) 


\section{(4-cyano pentanoic acid)yl ethyl trithiocarbonate (CPAETC)}

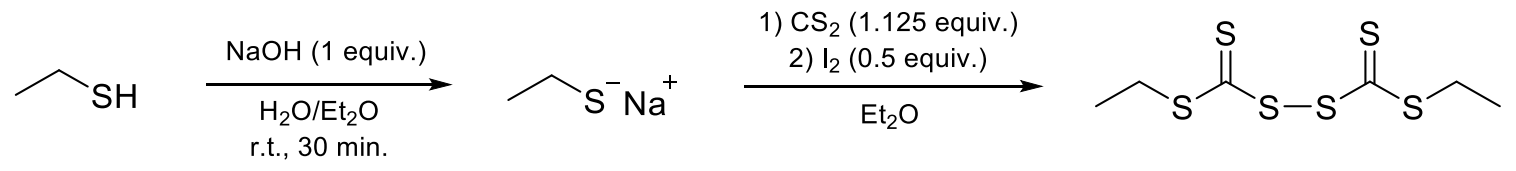

A solution of ethanethiol $(5 \mathrm{~mL}, 69.3 \mathrm{mmol})$ was suspended in diethyl ether $(50 \mathrm{~mL})$ under strong stirring at room temperature, to which a $27 \mathrm{wt} \%$ aqueous solution of sodium hydroxide $(\sim 10 \mathrm{~g}$, containing $2.704 \mathrm{~g}, 69.3 \mathrm{mmol}$ of $\mathrm{NaOH}$ ) was added. The clear, colorless solution was stirred for 30 min., then treated with carbon disulfide $(4.6 \mathrm{~mL}, 76.2 \mathrm{mmol})$ to give an orange solution. After further 30 min stirring, diethyl ether $(15 \mathrm{~mL})$ was added and the product reacted with a slow addition of iodine ( $4.8 \mathrm{~g}, 37.8 \mathrm{mmol})$. After $1.5 \mathrm{~h}$, diethyl ether $(30 \mathrm{~mL})$ was added and the ether phase washed twice with an aqueous sodium thiosulfate solution $(50 \mathrm{~mL})$ and once with water $(50 \mathrm{~mL})$. The ether phase was dried over magnesium sulfate, filtered, and the solvent removed under reduced pressure to give the intermediate product bis-(ethylsulfanylthiocarbonyl) disulfide as an orange oil. This was used unpurified in the subsequent step. ${ }^{1} \mathrm{H}-\mathrm{NMR}\left(400 \mathrm{MHz}, \mathrm{CDCl}_{3}, \mathrm{ppm}\right): \delta=3.31\left(4 \mathrm{H}, t,-\mathrm{CH}_{2}-\mathrm{S}\right)$, $1.36\left(6 \mathrm{H}, m,-\mathrm{CH}_{3}\right)$.<smiles>CCSC(=S)SSC(=S)SCC</smiles>

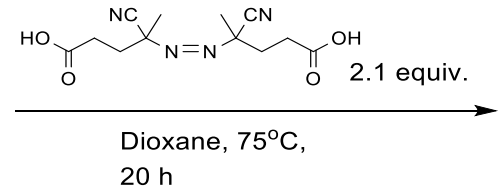<smiles>CCSC(=S)SC(C)(C#N)CCC(=O)O</smiles>

To a solution of bis-(ethylsulfanylthiocarbonyl) disulfide $(2.27 \mathrm{~g}, 8.3 \mathrm{mmol})$ in dioxane $(25 \mathrm{~mL})$, 4,4'-Azobis(4-cyanovaleric acid) (4.6 g, $16.4 \mathrm{mmol})$ was added and the mixture was stirred for $20 \mathrm{~h}$ at $75^{\circ} \mathrm{C}$. Solvent was removed under reduced pressure, and the product purified by silica gel column chromatography (eluent: n-Hexane/EtOAc, 50/50) to afford the expected compound as a dark orange oil (1.51 g, $5.8 \mathrm{mmol}, 70 \%$ yield) that solidified on refrigeration. ${ }^{1} \mathrm{H}-\mathrm{NMR}\left(400 \mathrm{MHz}, \mathrm{CDCl}_{3}, \mathrm{ppm}\right)$ : $\delta=3.35\left(2 \mathrm{H}, t,-\mathrm{CH}_{2}-\mathrm{S}\right), 2.71-2.67\left(m, 2 \mathrm{H},-\mathrm{CH}_{2^{-}}\right), 2.58-2.36\left(2 m, 2 \mathrm{H},-\mathrm{CH}_{2^{-}}\right), 1.89\left(3 \mathrm{H}, s,-\mathrm{CH}_{3}^{-}\right)$, $1.36\left(3 \mathrm{H}, t,-\mathrm{CH}_{3}\right)$. 


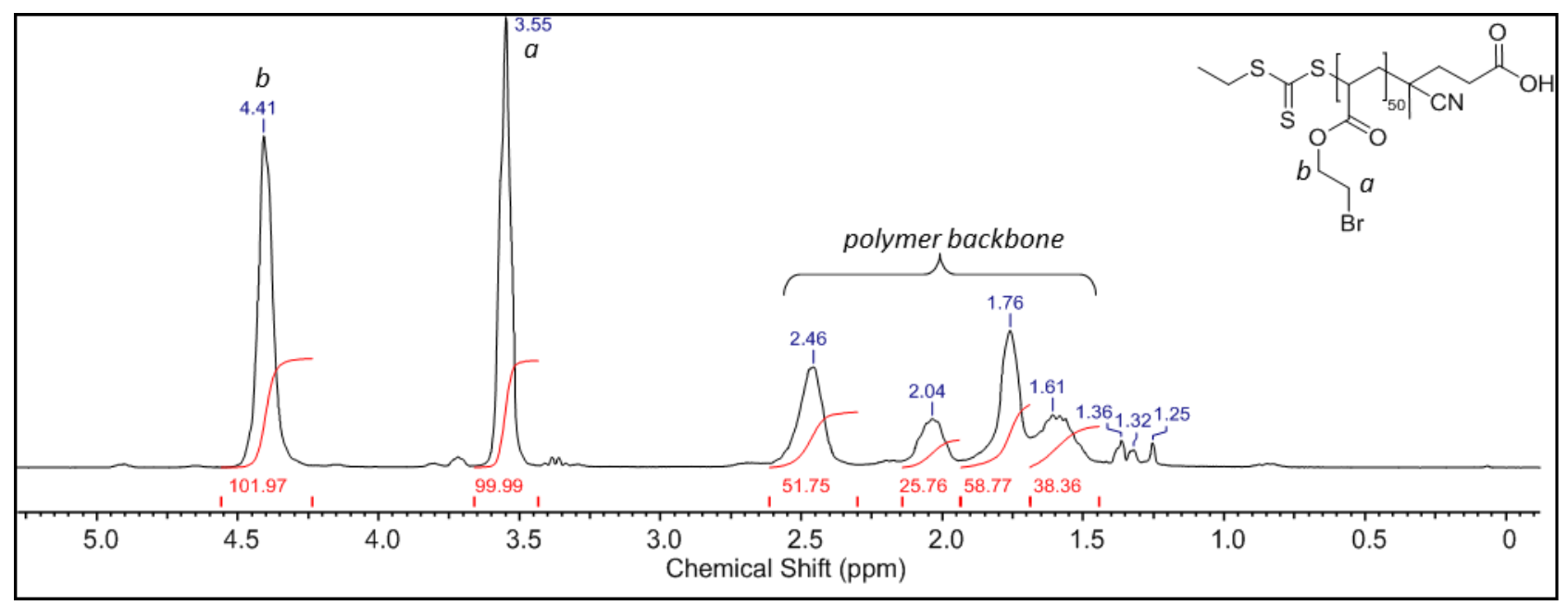

S 1: ${ }^{1} \mathrm{H} \mathrm{NMR}$ in $\mathrm{CDCl}_{3}$ of pBEA $A_{50}$.

\section{Block Copolymers}

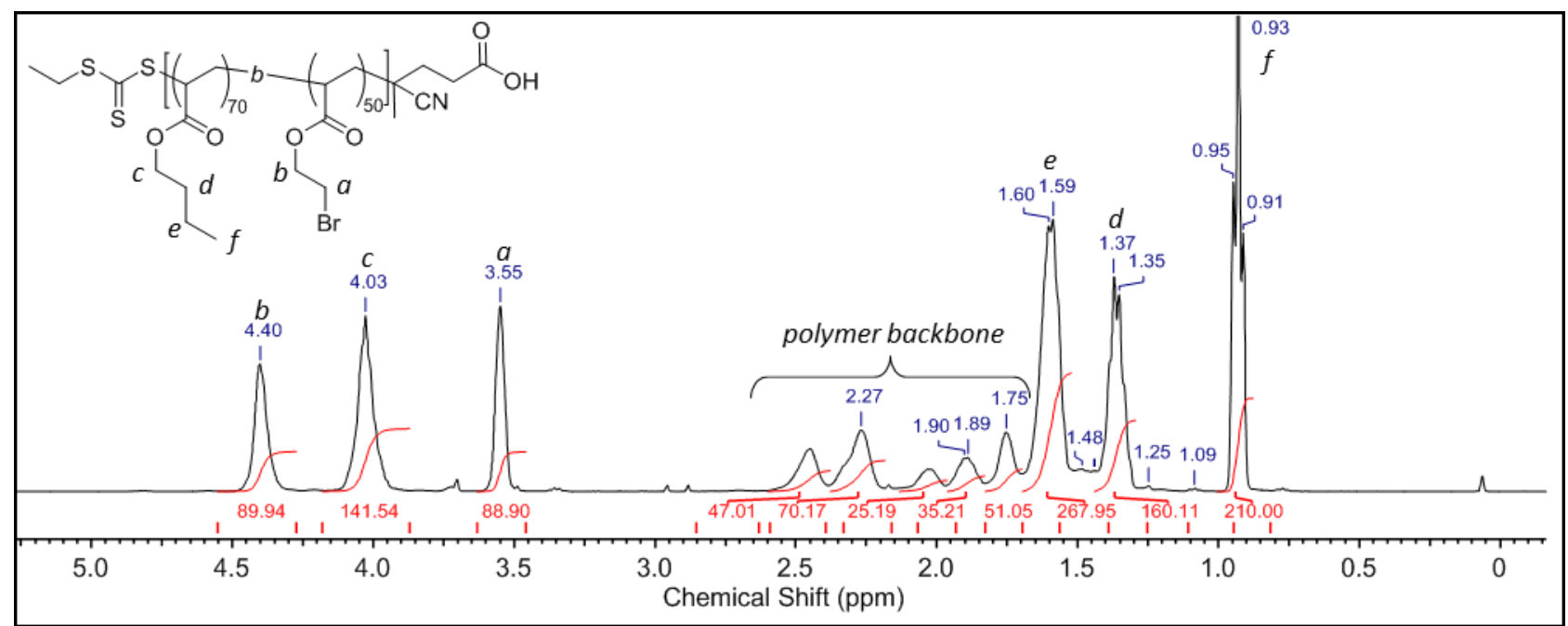

$S 2:{ }^{1} \mathrm{H} \mathrm{NMR}$ in $\mathrm{CDCl}_{3}$ of $p B E A_{50}-b-p B A_{70}$ (from macro-CTA S1). 


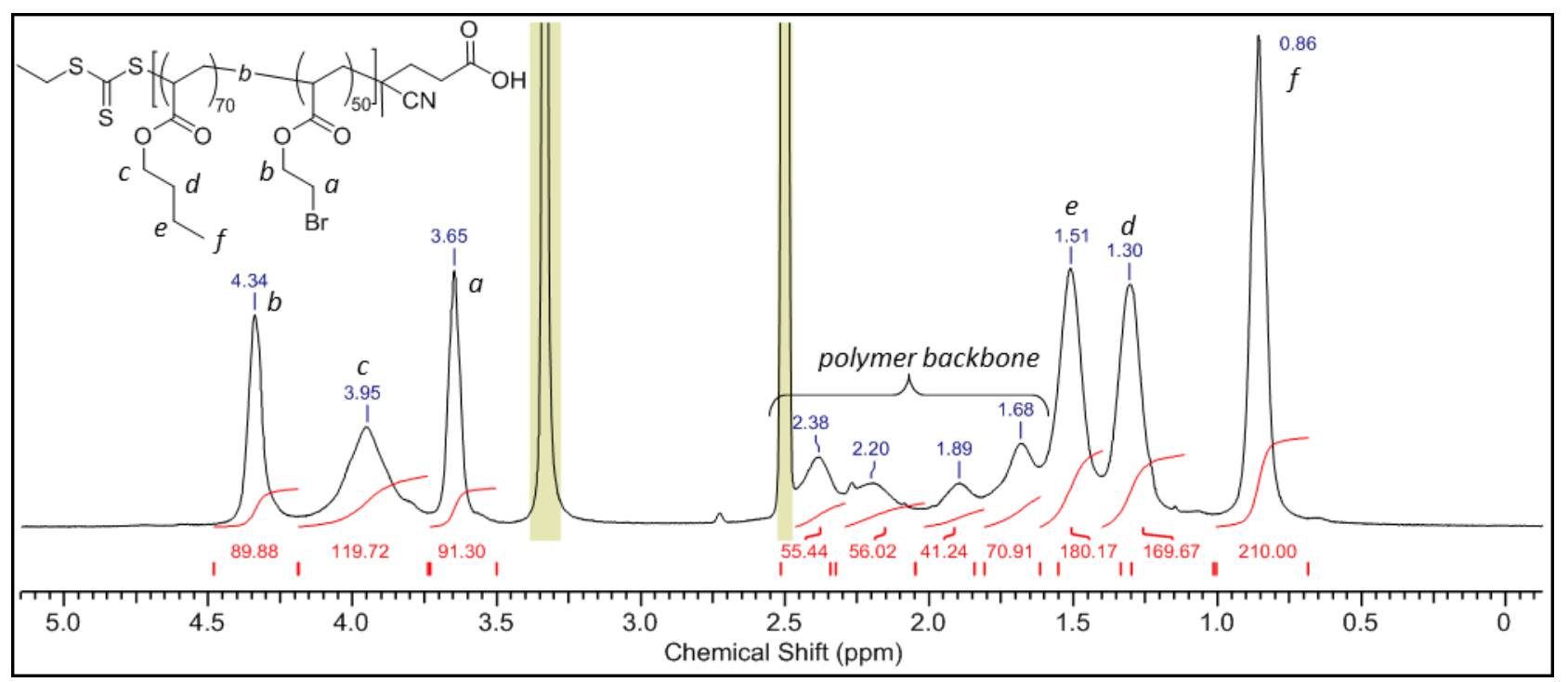

S $3:{ }^{1} H$ NMR in DMSO-d ${ }_{6}$ of $p B E A_{50}-b-p B A_{70}$ (from macro-CTA S1).

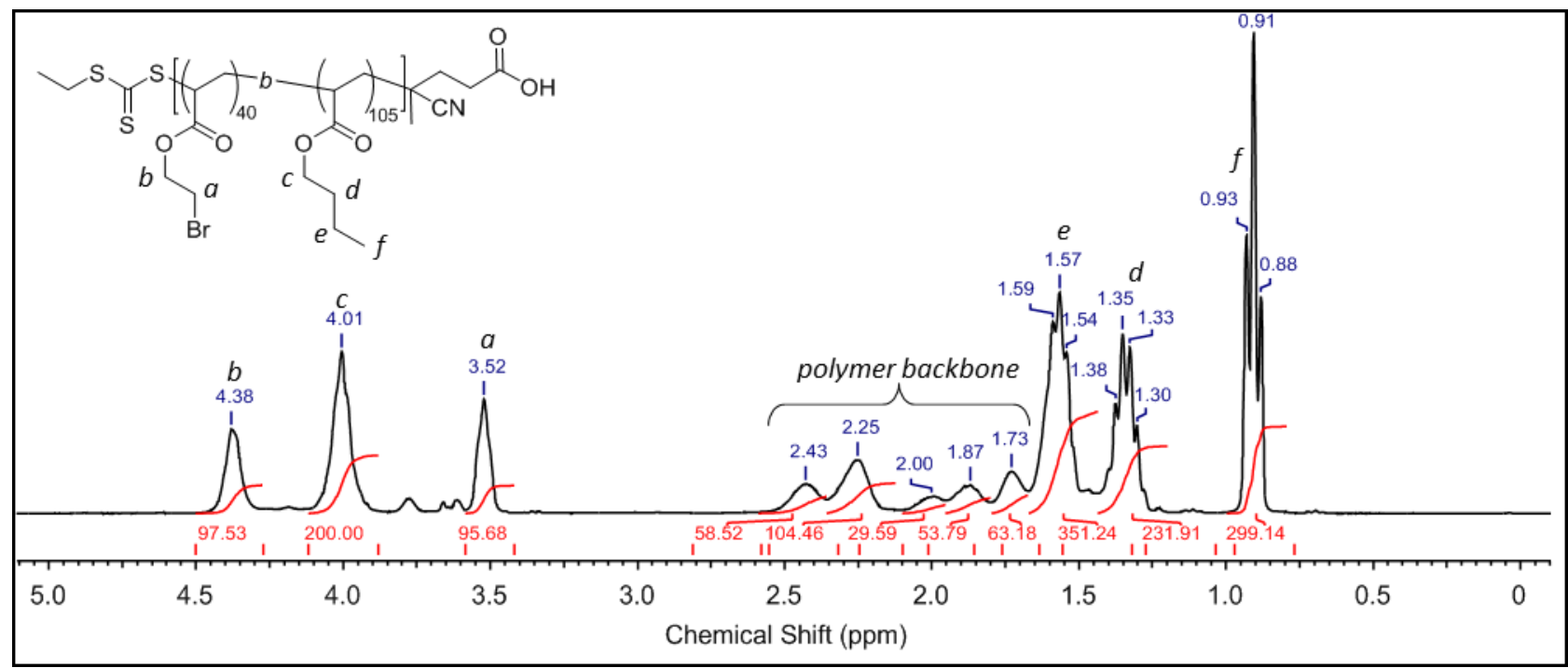

$S 4:{ }^{1} \mathrm{H} \mathrm{NMR}$ in $\mathrm{CDCl}_{3}$ of $p B A_{105}-b-p B E A_{40}$ (from macro-CTA S3).

Table 1: Summary of BEA RAFT homopolymerization for use as macro-CTA.

\begin{tabular}{ccccccc}
\hline Polymer & {$[\mathrm{M}]_{0} /[\mathrm{CTA}]_{0}$} & {$[\mathrm{CTA}]_{0} /[\mathrm{I}]_{0}$} & Conv. $^{a}(\%)$ & $M_{\mathrm{n}, \mathrm{th}}{ }^{b}$ & $M_{\mathrm{n}, \mathrm{SEC}}{ }^{c}$ & $Ð$ \\
\hline S1 & 55 & 10 & 92 & 9100 & 7100 & 1.12 \\
S2 & 61 & 10 & 75 & 7800 & 7000 & 1.09 \\
${ }^{a}$ Determined from ${ }^{1} \mathrm{H} \mathrm{NMR}^{b}{ }^{b}$ Calculated from the conversion and characteristics of the \\
parent polymer. ${ }^{c}$ From SEC analysis (DMF LiBr, pMMA-Std.).
\end{tabular}


Table 2: Summary of BA RAFT homopolymerization for use as macro-CTA.

\begin{tabular}{ccccccc}
\hline Polymer & {$[\mathrm{M}]_{0} /[\mathrm{CTA}]_{0}$} & {$[\mathrm{CTA}]_{0} /[\mathrm{I}]_{0}$} & Conv. $^{a}(\%)$ & $M_{\mathrm{n}, \mathrm{th}}{ }^{b}$ & $M_{\mathrm{n}, \mathrm{SEC}}{ }^{c}$ & $Ð$ \\
\hline S3 & 150 & 10 & 74 & 13900 & 15400 & 1.08 \\
${ }^{a}$ Determined from ${ }^{1} \mathrm{H}$ NMR.${ }^{b}$ Calculated from the conversion and characteristics of the \\
parent polymer. ${ }^{c}$ From SEC analysis (DMF LiBr, pMMA-Std.).
\end{tabular}

Table 3: Summary of RAFT chain extensions with BA.

\begin{tabular}{ccccccc}
\hline $\begin{array}{c}\text { Macro-CTA } \\
\text { Used }\end{array}$ & {$[\mathrm{M}]_{0} /[\mathrm{CTA}]_{0}$} & {$[\mathrm{CTA}]_{0} /[\mathrm{I}]_{0}$} & Conv. $^{a}(\%)$ & $M_{\mathrm{n}, \mathrm{th}}{ }^{b}$ & $M_{\mathrm{n}, \mathrm{SEC}}{ }^{c}$ & $Ð$ \\
\hline S1 & 120 & 10 & 64 & 22000 & 18200 & 1.25 \\
S2 & 150 & 10 & 70 & 23000 & 15900 & 1.20 \\
${ }^{a}$ Determined from & ${ }^{1} \mathrm{H} \mathrm{NMR}^{b}{ }^{b}$ Calculated from the conversion and characteristics of the parent \\
polymer. ${ }^{c}$ From SEC analysis (DMF LiBr, pMMA-Std.).
\end{tabular}

Table 4: Summary of RAFT chain extensions with BEA.

\begin{tabular}{lcccccc}
\hline $\begin{array}{c}\text { Macro-CTA } \\
\text { Used }\end{array}$ & {$[\mathrm{M}]_{0} /[\mathrm{CTA}]_{0}$} & {$[\mathrm{CTA}]_{0} /[\mathrm{I}]_{0}$} & Conv. $^{a}(\%)$ & $M_{\mathrm{n}, \mathrm{th}}{ }^{b}$ & $M_{\mathrm{n}, \mathrm{SEC}}{ }^{c}$ & $Ð$ \\
\hline $\mathbf{S 3}$ & 60 & 10 & 68 & 20700 & 22800 & 1.08 \\
& & &
\end{tabular}

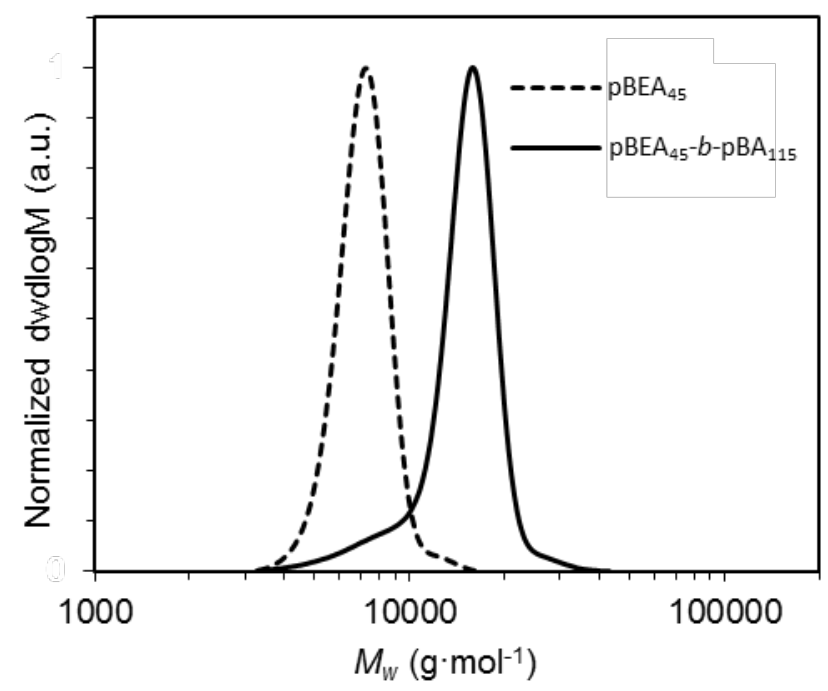

S 5: SEC trace of $\mathrm{PBEA}_{45}$ macro-CTA (S2) polymerized to $75 \%$ conversion, and subsequent chain extension with $p B A_{115}$. 
Substitution with Trimethyl amine

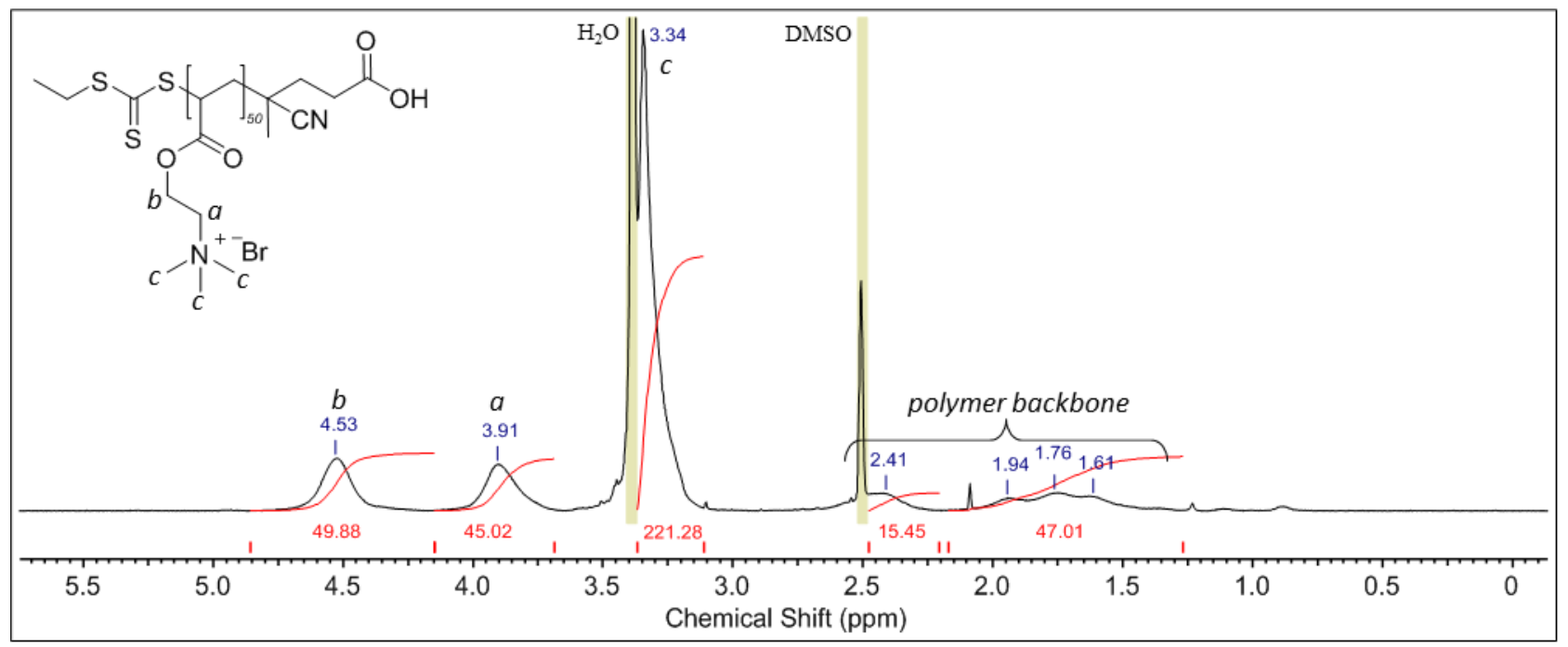

S 6: ${ }^{1} \mathrm{H} N \mathrm{NM}$ in DMSO-d ${ }_{6}$ of product from trimethyl amine substitution of $p B E A_{50}$.

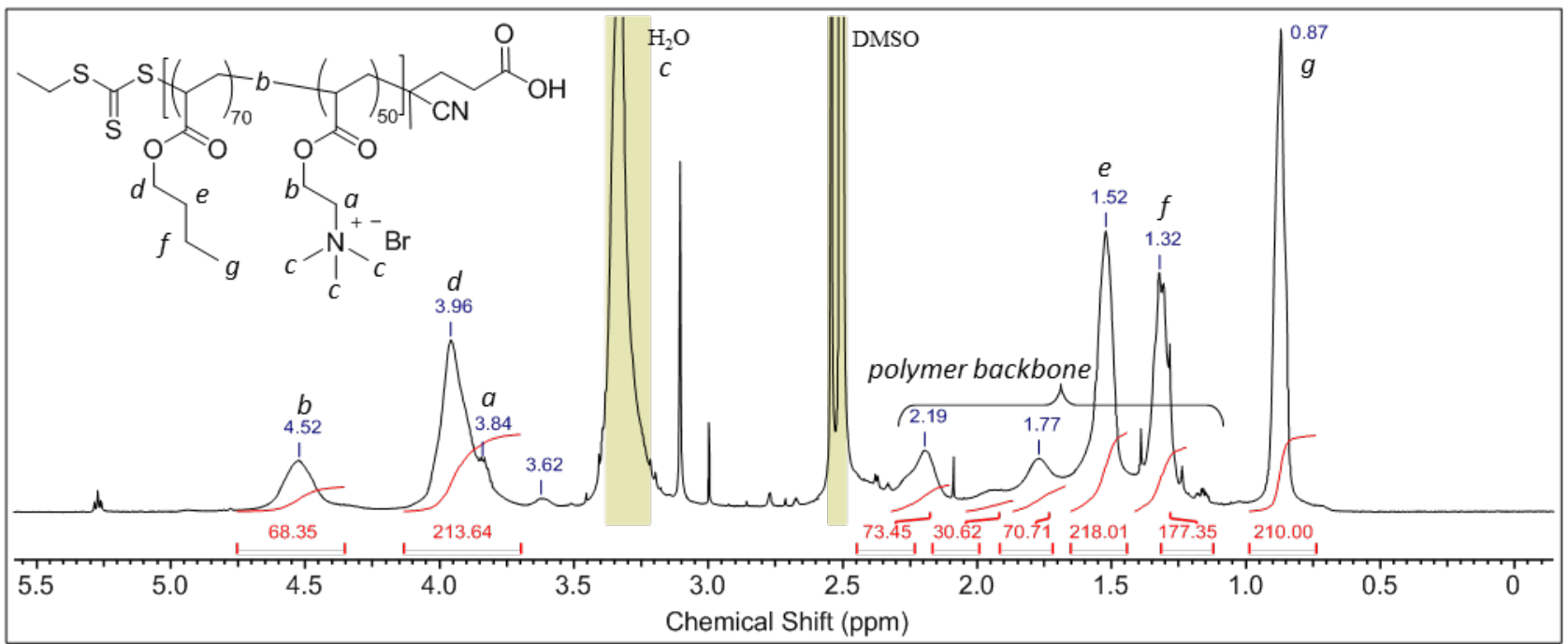

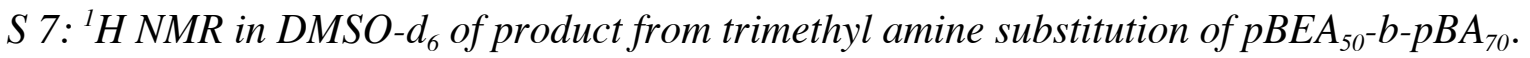


Substitution with Trimethyl phosphine

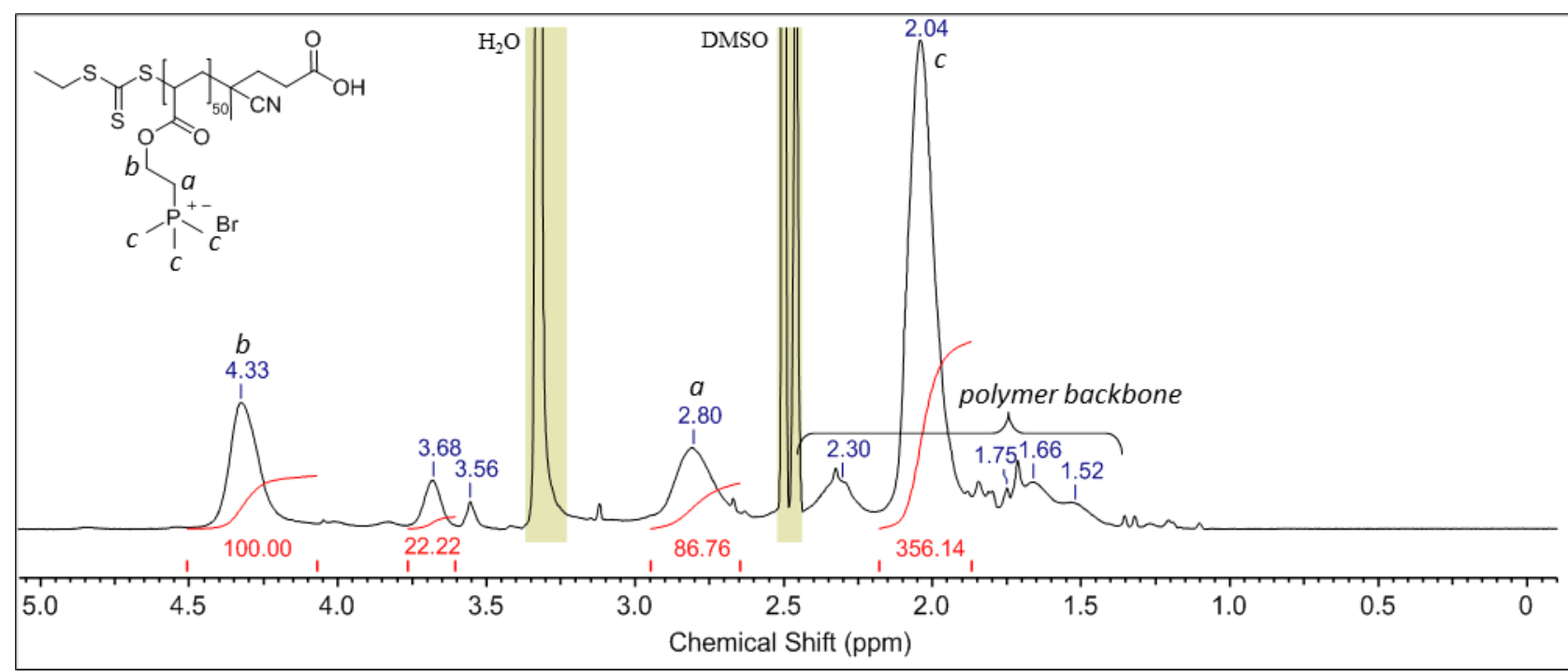

$S$ 8: ${ }^{1} H$ NMR in DMSO-d ${ }_{6}$ of product from trimethyl phosphine substitution of $p B E A_{50}$.

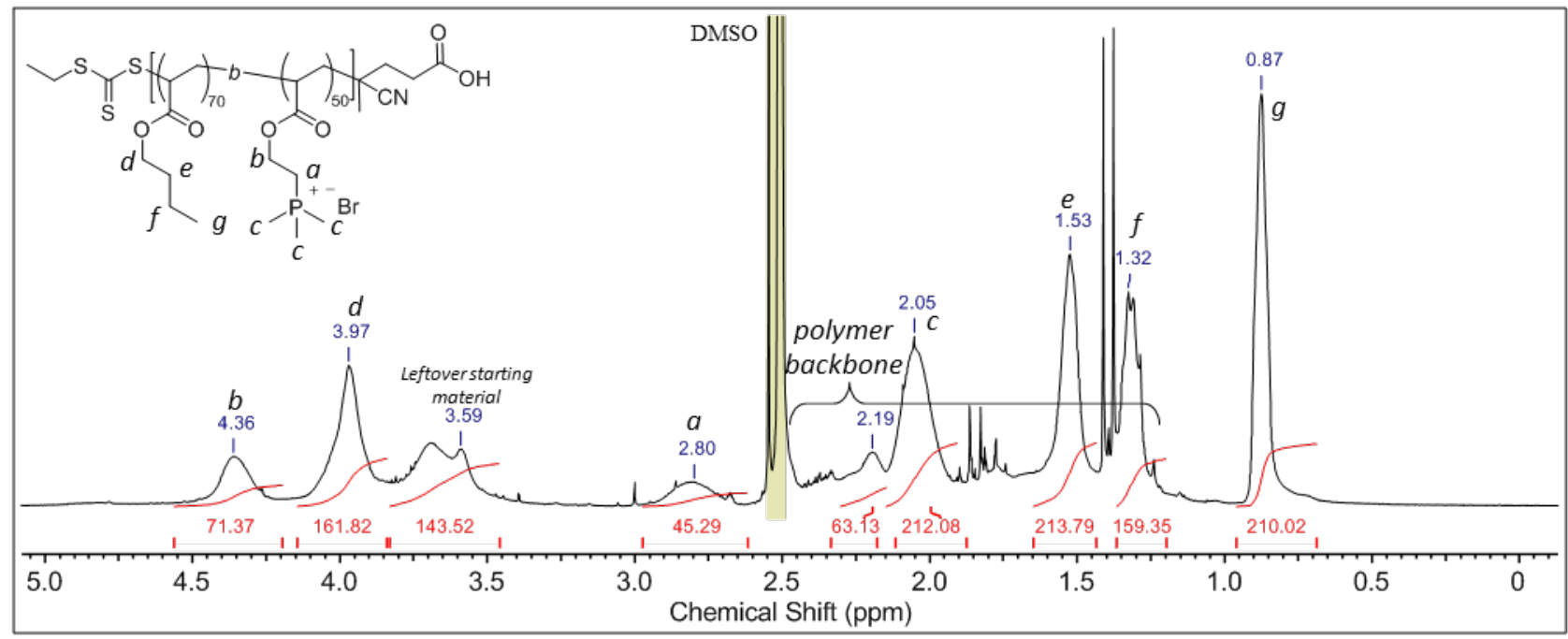

S 9: ${ }^{1} H$ NMR in DMSO-d $d_{6}$ of product from trimethyl phosphine substitution of $p B E A_{50}-b-p B A_{70}$.

Table 5: DLS and Zeta Potential of block copolymers after substitution with trimethyl amine (pTMABEA) and trimethyl phosphine (pTMPBEA).

\begin{tabular}{|c|c|c|c|c|}
\hline Sample & \multicolumn{2}{|c|}{ pTMABEA $\left(\mathbf{N}^{+}\right)$} & \multicolumn{2}{c|}{ pTMPBEA $\left(\mathbf{P}^{+}\right)$} \\
\hline Filtered & $\mathrm{N}$ & $\mathrm{Y}$ & $\mathrm{N}$ & $\mathrm{Y}$ \\
\hline Size (d.nm) & 163 & 137 & 127 & 124 \\
\hline PDI & 0.272 & 0.202 & 0.264 & 0.205 \\
\hline $\begin{array}{c}\text { Zeta Potential } \\
(\mathbf{m V})\end{array}$ & \multicolumn{2}{|c|}{44.6} & \multicolumn{2}{c|}{38.26} \\
\hline
\end{tabular}



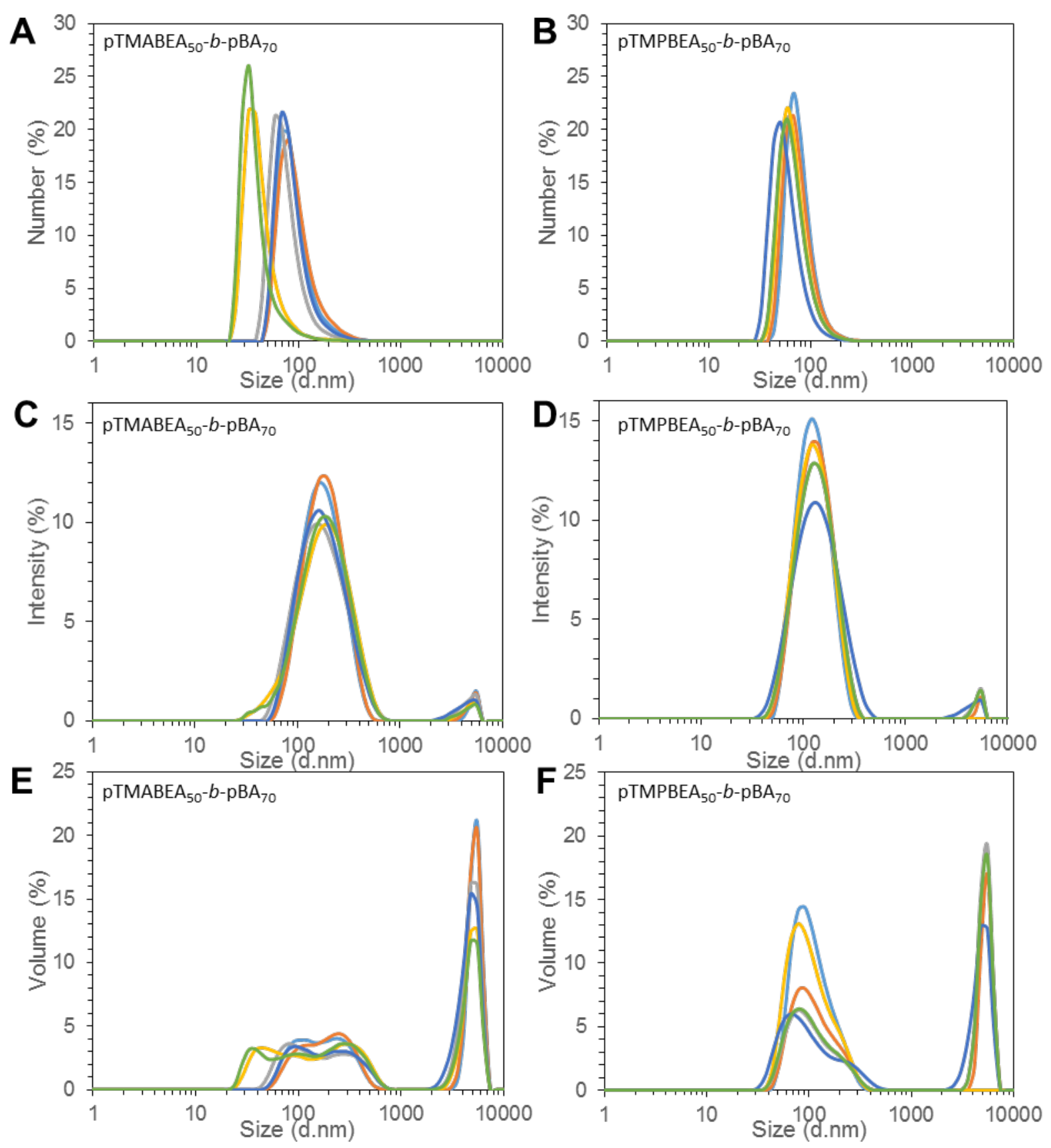

S 10: DLS size distribution plots: by Number - $(A)$ and $(B)$; by Intensity $(C)$ and $(D)$; by Volume $(E)$ and $(F)$. Plots $(A),(C)$, and $(E)$ correspond to $p T M P A E A_{50}-b-p B A_{70}$. Plots $(B),(D)$, and $(E)$ correspond to $p T M P B E A_{50}-b-p B A_{70}$. 
Substitution with Tetraethylammonium sulfite
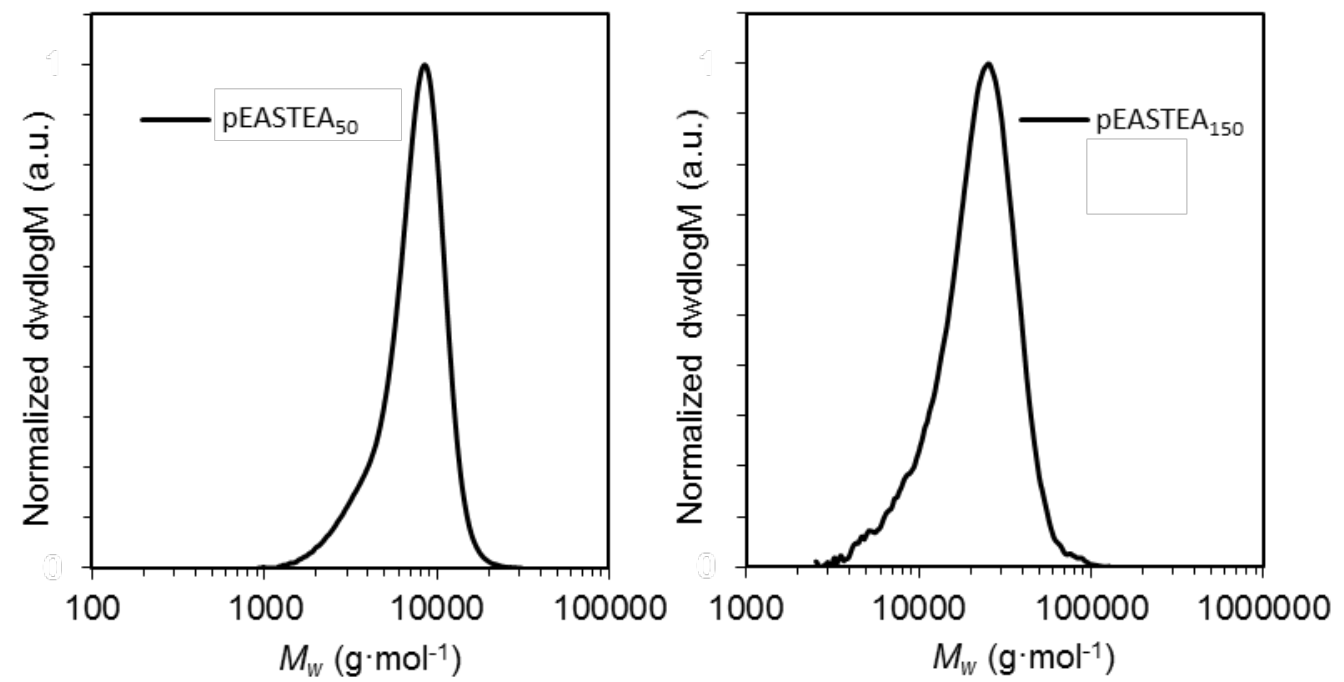

S 11: SEC trace of product of tetraethylammonium sulfite substitution of $p B E A_{50}$ and $p B E A_{150}$.

\section{Substitution with Sodium azide}

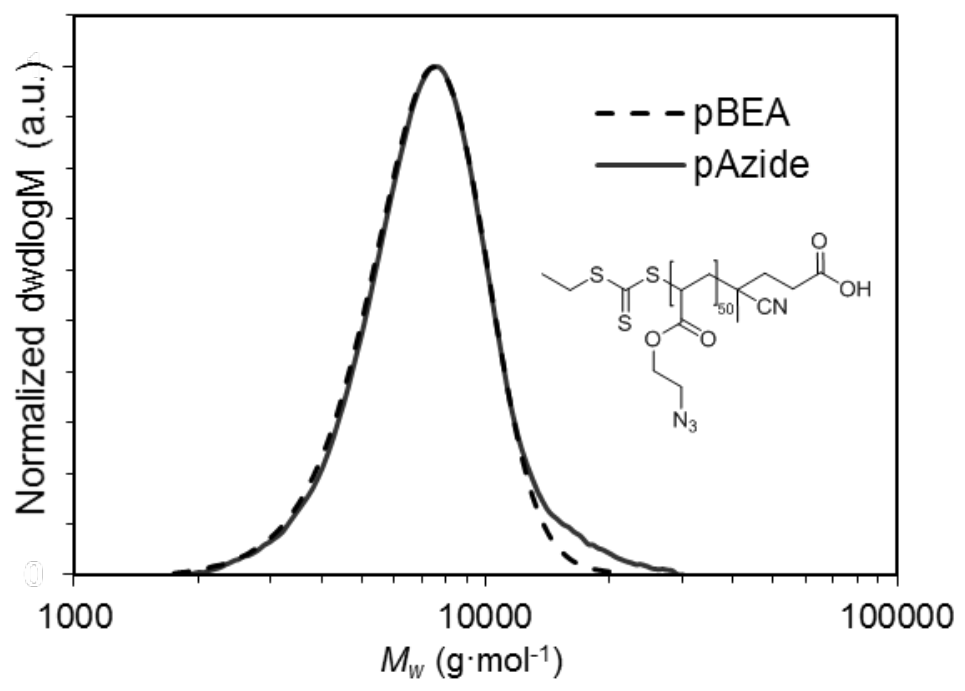

S 12: SEC trace of product of sodium azide substitution of $p B E A_{50}$. 


\section{Substitution with Thiophenol}

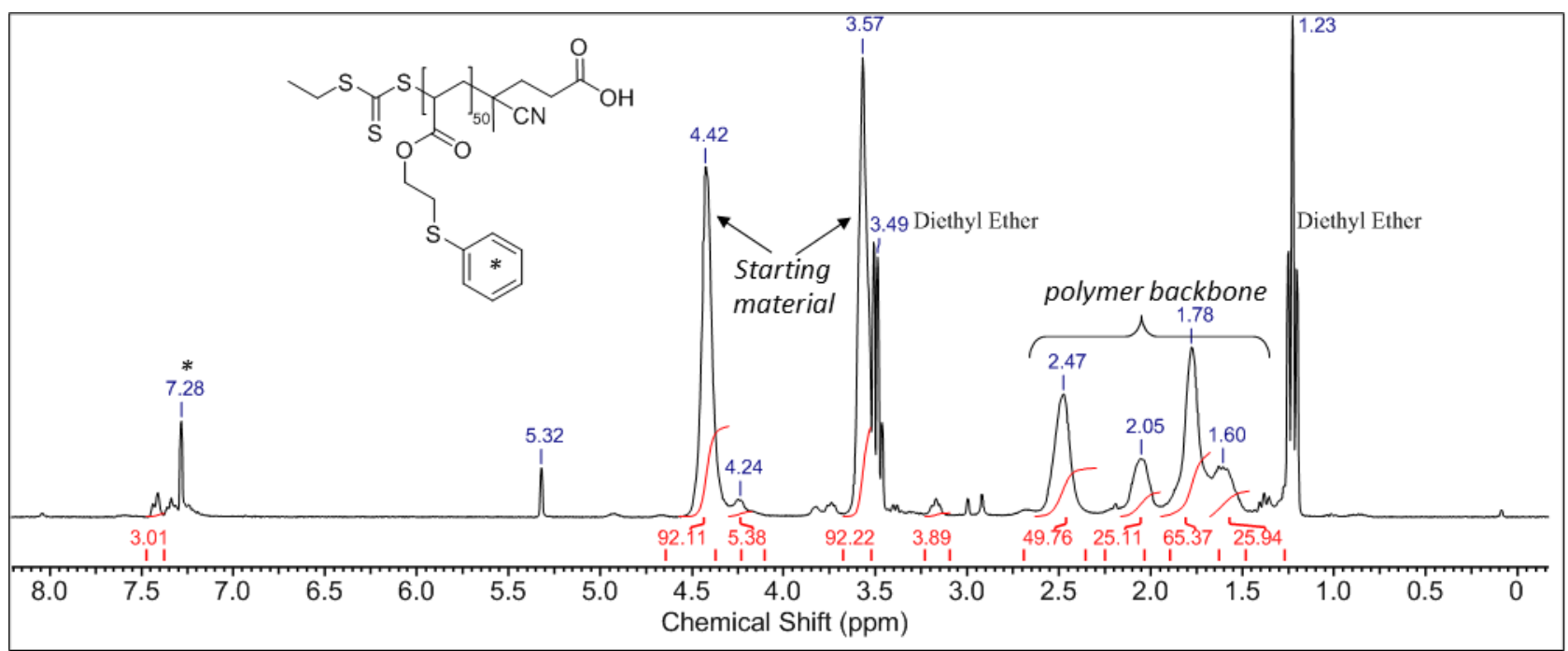

$S$ 13: ${ }^{1} \mathrm{H} \mathrm{NMR}$ in $\mathrm{CDCl}_{3}$ of the precipitated product of the thiophenol substitution of pBEA $A_{50}$ conducted without base.

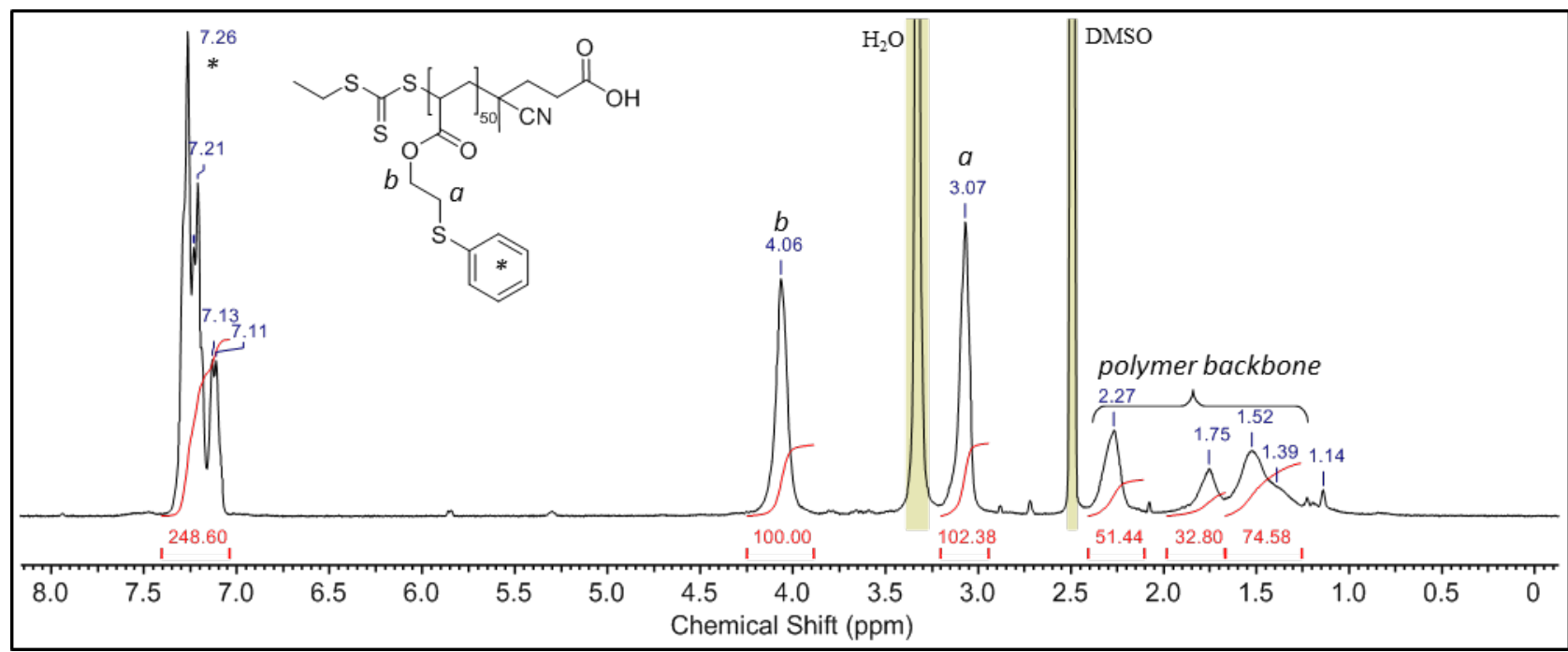

$S 14:{ }^{1} \mathrm{H} \mathrm{NMR}$ in $\mathrm{CDCl}_{3}$ of the precipitated product of the thiophenol substitution of $p B E A_{50}$ conducted with DIPEA. 
Substitution with 1- $\beta$-D-Thioglucose

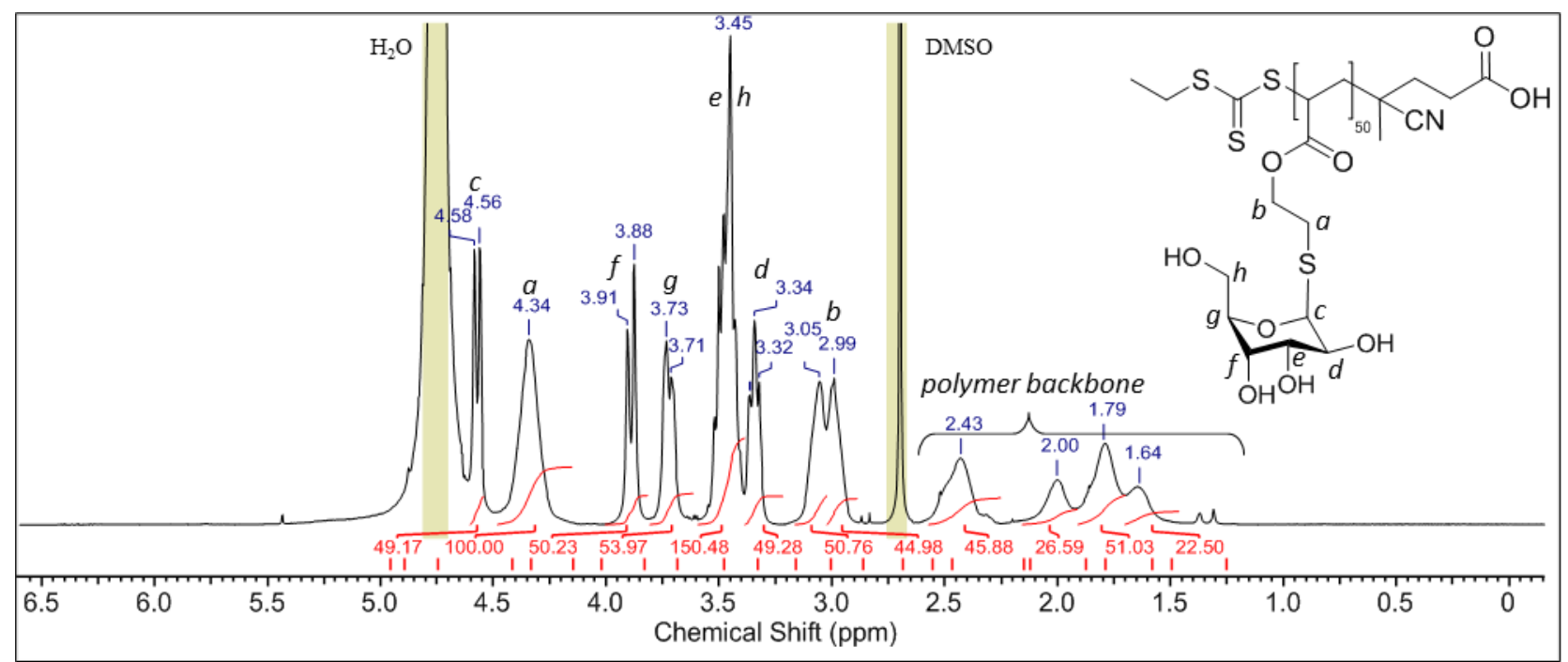

S 15: ${ }^{1} \mathrm{H} N M R$ in $D_{2} O$ of poly(1- $\beta$-D-Thioglucose $)_{50}$.

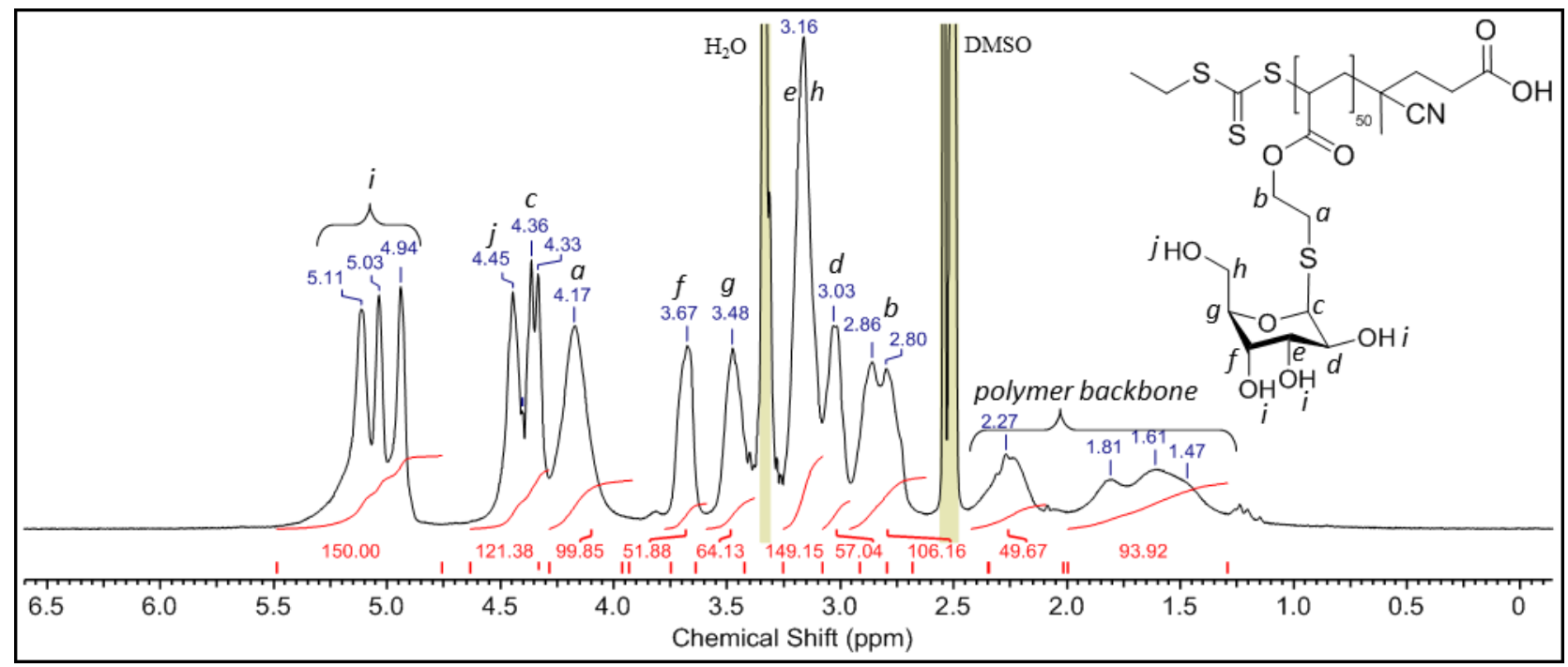

S 16: ${ }^{1} H$ NMR in DMSO-d ${ }_{6}$ of poly $(1-\beta \text {-D-Thioglucose })_{50}$. 


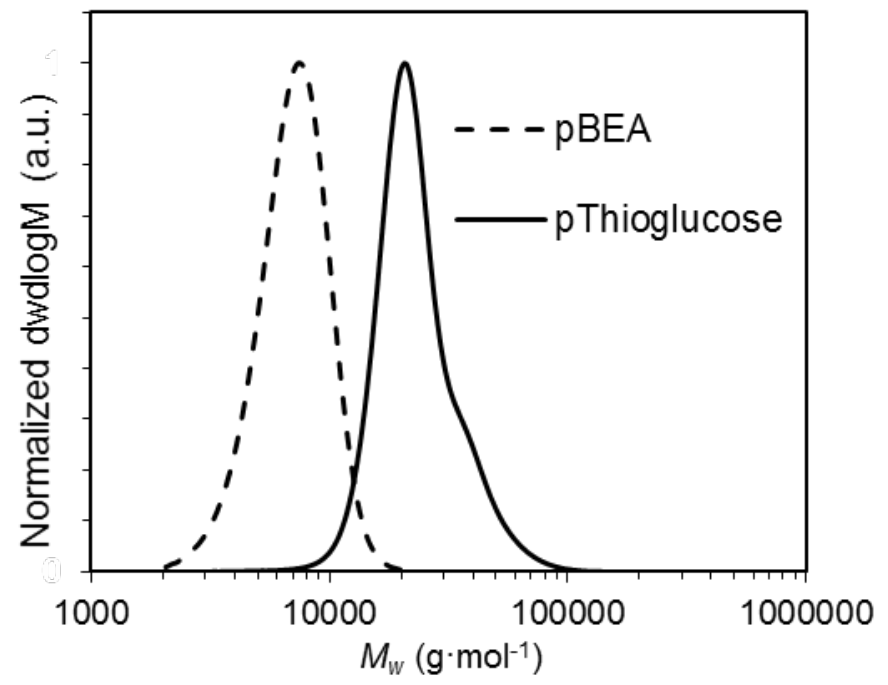

$S$ 17: SEC trace of product of 1- $\beta$-D-Thioglucose substitution of $p B E A_{50}$. 